$\underline{\text { Research Article }}$

\title{
Predictors and facilitators of gender-based violence in sub-Saharan Africa: a rapid review
}

\author{
Ifeyinwa C Akamike', Chigozie J Uneke', Henry C Uro-Chukwu', Ijeoma N Okedo-Alex', Onyedikachi E Chukwu \\ ${ }^{1}$ African Institute for Health Policy and Health Systems, Ebonyi State University, Abakaliki, Ebonyi State, Nigeria \\ Keywords: sub-saharan africa, gender-based violence, global health \\ https://doi.org/10.29392/joghr.3.e2019076
}

\section{Journal of Global Health Reports}

Vol. 3, 2019

\begin{abstract}
Background
An understanding of factors associated with gender-based violence is essential for developing evidence-based interventions that are necessary for the prevention of violence against women. The objective of this study was to summarize the predictors of gender-based violence.
\end{abstract}

\section{Methods}

A PubMed search was carried out in January 2019 and identified primary quantitative research studies that measured predictors of any form of gender-based violence in sub-Saharan Africa and were published in the English language between January 2000 and December 2018. The categories of keywords used for the search were facilitators, barriers, predictors, gender-based violence, Africa.

\section{Results}

A total of 21 studies were reviewed. The prevalence of gender-based violence in this review ranges from $11.6 \%$ to $75.6 \%$. The results show that predictors include factors such as socio-demographic factors, individual factors, family factors, spouse's/partner's habit, and experience in the past. Ten studies reported socio-economic predictors of gender-based violence while eight of the studies cited predictors specific to the individual. Eight of the studies reported predictors due to partner/spouse's habits, and only two studies reported family-related predictors. Seven studies reported predictors due to previous experience. Lower educational status, being married, being involved in sex work, having experienced abuse in the past, substance abuse by partner, having a gender-biased attitude, younger age, lower socioeconomic status, urban residence, having a promiscuous partner, and poor social support were found to be predictors of gender-based violence. Perpetrator factors identified include sexual history, previous experience of abuse, educational status, substance use, gender-biased attitude, and having experienced abuse of the mother.

\section{Conclusions}

The study concludes that an inter-sectoral approach is necessary to address the problem of gender-based violence. Community engagement including stakeholder engagement is also a vital instrument in addressing gender-based violence.

Gender-based violence which is a well-known public health concern ${ }^{1-4}$ has had a significant impact on women's health and wellbeing. ${ }^{1,4}$ It increases women's long-term risk of health problems in addition to causing injury. Gender-based violence is violence directed against a person because of their gender. Both women and men experience gender-based violence but the majority of victims are women and girls. ${ }^{5}$ Even though women can be violent and in some same-sex relationships, abuse exists, the vast majority of partner abuse is perpetrated by men against their female partners. ${ }^{6}$ Violence against women includes any act of verbal or physical force, coercion or life-threatening de- privation, directed at an individual woman or girl that causes physical or psychological harm, humiliation or arbitrary deprivation of liberty and that perpetuates female subordination. ${ }^{6,7}$ There are various forms of gender-based violence which include physical, sexual, and psychological abuse from intimate partners, sexual violence by non-partners, sexual abuse of girls, and acts such as trafficking women for sex. ${ }^{1}$ However, the most persistent form of gender violence is the abuse of women by intimate male partners. ${ }^{3,6}$

The health outcomes of violence against women include suicide, injury, functional impairment, permanent disabil- 
ity, chronic pain syndrome, gastrointestinal disorders, posttraumatic stress depression, low self-esteem, substance abuse, unwanted pregnancy, sexually transmitted infections, HIV/AIDs, gynecological disorders, among others. ${ }^{6}$

Levels of violence vary significantly between settings, both among and within countries. Globally, it is estimated that $30 \%$ of ever-partnered women aged 15 years and older have experienced physical and/or sexual intimate partner violence (IPV) in their lifetimes. ${ }^{8}$ In the western countries, the lifetime prevalence of physical or sexual violence among ever- partnered women ranges from $15 \%$ to $37 \%{ }^{4}$ Studies in sub-Saharan Africa have reported prevalence rates of gender-based violence ranging from $11.6 \%$ to $75.6 \% .^{3,9-13}$

Recognising the importance of addressing violence against women, the United Nations Fourth World Conference on Women identified violence against women as one of the critical areas of concern needing action in $1995 .{ }^{14}$

Appropriate and effective policy responses to prevent and address the effects of gender-based violence depend on an understanding of the prevalence, and root causes and factors associated with gender-based violence. Because of these high rates and negative repercussions on the health and life of women and their children, several studies have sought to identify factors associated with violence. ${ }^{15}$ However, this review aimed to summarise the predictors and facilitators of gender-based violence in the sub-Saharan African region.

\section{METHODS}

The Preferred Reporting Items for Systematic Reviews and Meta-Analyses (PRISMA) guidelines for systematic reviews and meta-analyses, ${ }^{16}$ was used in screening studies for eligibility.

\section{SEARCH STRATEGY AND SELECTION CRITERIA}

A PubMed search was performed in January 2019. Studies that investigated predictors of gender-based violence were selected. The search strategies/keywords used were in four categories. Category 1: facilitators, gender-based violence, Africa, Category 2: predictors, gender-based violence, Africa, Category 3: gender-based violence, Africa and Category 4: Barriers, gender-based violence, Africa. The inclusion criteria included studies that were carried out in sub-Saharan Africa and published in English language, published between the years January 2000 and December 2018, measured predictors of any form of gender-based violence, and used any quantitative study design.

The search strategy is seen in Appendix S1 of the Online Supplementary Document.

\section{DATA EXTRACTION}

A data extraction form was developed and reviewed by all reviewers. Data were extracted for each paper using the standardised form with the following domains; the name of the first author and year of publication, study location, study design, study population/sample size, prevalence, and predictors. Two of the reviewers extracted the data in- dependently and resolved discrepancies by discussion and consensus. The references were tracked using the Mendeley reference manager.

\section{QUALITY APPRAISAL}

The quality of the studies included in this review was appraised using the Quality Assessment Tool for Observational Cohort and Cross-Sectional Studies (Appendix S2 in the Online Supplementary Document). This quality assessment tool has been used in other systematic reviews. ${ }^{17,18}$ The tool consists of fourteen questions assessing different aspects of a study including but not limited to the definition of objectives, study population, sampling strategy, sample size, and statistical analyses. Each question is scored as Yes (1) or No (0), and others (CD, cannot determine; NA, not applicable and NR, not reported). The appropriate criteria based on study design was used to assess each study and the elements of the criteria which did not apply to a particular study were marked as not applicable. The quality assessment was done by the first author and two other co-authors. All the studies fulfilled the quality criteria except for eleven studies that did not report on sample size.

\section{STUDY SELECTION}

A total of 493 publications were identified from the search. Categories one, two, three and four yielded 6, 12, 443 and 32 entries respectively (Figure 1).

Citations identified through the search strategy were initially reviewed for inclusion based on information contained in titles. Four hundred and sixty-eight were excluded based on the title. Twenty-five of the citations were included based on the abstracts. However, 4 publications were duplicated and after screening out duplicates, the remaining 21 studies were reviewed. Full-text articles were obtained for all eligible studies and for those requiring further review to determine eligibility. All the 21 articles were included for the review.

\section{RESULTS}

Twenty-one studies that met inclusion criteria were identified and used for this review (Table 1). Figure 1 shows a summary of the search results. Fifteen of the studies were carried out among women alone, two among men alone and four among men and women or couples. All the studies used a cross-sectional study design except one which was a baseline survey of a cluster-randomized trial (Table 1).

\section{SEARCH RESULTS}

Twenty-one studies carried out in ten countries in sub-Saharan Africa, which provided sufficient information were identified and used for this review. Figure 1 shows a summary of the search results. Fifteen of the studies were carried out among women alone, two among men alone and four among men and women or couples. All the studies used a cross-sectional study design except one which was a baseline survey of a cluster-randomized trial. 
Table 1. Summary of all studies

\begin{tabular}{|c|c|c|c|}
\hline $\begin{array}{l}\text { Year of publication/ } \\
\text { Location }\end{array}$ & Study design & $\begin{array}{l}\text { Study population/ } \\
\text { sample size }\end{array}$ & Predictors/facilitators \\
\hline 2015/Ethiopia ${ }^{3}$ & $\begin{array}{l}\text { Cross-sectional } \\
\text { study }\end{array}$ & 250/Women & $\begin{array}{l}\text { Basic literacy, completion of only elementary school, completion of only high school, being married, engaging in sex work for 1-4 } \\
\text { years and drug use }\end{array}$ \\
\hline 2012/ Nigeria ${ }^{13}$ & Cross-sectional & 924/women & $\begin{array}{l}\text { Previous experience of psychological abuse, sexual abuse, having attitudes supportive of IPV, partner's daily alcohol consumption, } \\
\text { and previous engagement in a physical fight }\end{array}$ \\
\hline 2011/Nigeria ${ }^{12}$ & Cross-sectional & $\begin{array}{l}\text { 300/female } \\
\text { university } \\
\text { students }\end{array}$ & Religious affiliation, ethnicity, indigeneship, marital status, campus residence and faculty affiliation \\
\hline 2018/Ghana ${ }^{11}$ & Cross-sectional & 2000/women & $\begin{array}{l}\text { Depression, disability, witnessing abuse of mother, experience of childhood sexual abuse, having had multiple sexual partners in } \\
\text { past year, control by male partner, male partner alcohol use in past year and male partner infidelity }\end{array}$ \\
\hline 2017/Kenya ${ }^{10}$ & Cross-sectional & $\begin{array}{l}\text { 238/antenatal } \\
\text { women }\end{array}$ & Alcohol intake by partner and partner's level of education, age of partner and age of pregnant women \\
\hline 2017/Kenya9 & Cross-sectional & $\begin{array}{l}8003(582 \text { girls } \\
\text { and } 7421 \\
\text { women), }\end{array}$ & Being married or cohabiting, low education, and reporting forced sex in the last 12 months \\
\hline 2018/Uganda ${ }^{19}$ & $\begin{array}{l}\text { Community- } \\
\text { based cross- } \\
\text { sectional study }\end{array}$ & 379 women & $\begin{array}{l}\text { Reporting recent client violence, doing what their partner wanted, and forced sexual debut, recent police arrest and/or } \\
\text { incarceration }\end{array}$ \\
\hline 2017/Rwanda 20 & Cross-sectional & 921 women & Low socioeconomic status, young age, living in urban areas and poor social support \\
\hline $\begin{array}{l}\text { 2016/South } \\
\text { Africa21 }\end{array}$ & Cross-sectional & $\begin{array}{l}1817 \text { Female Sex } \\
\text { Workers }\end{array}$ & $\begin{array}{l}\text { Inconsistent condom use with clients being offered more money for condomless sex, having had a condom slip or break and } \\
\text { difficulty suggesting condoms with non-paying partners }\end{array}$ \\
\hline 2016/Ethiopia 22 & Cross-sectional & $\begin{array}{l}\text { married pregnant } \\
\text { women/2021 }\end{array}$ & Having ever lived with partner's family (Protective). Dowry payment (Protective) \\
\hline $\begin{array}{l}\text { 2013/South } \\
\text { Africa23 }\end{array}$ & Cross-sectional & 1,388 women & Drinking and sexual risk behaviors \\
\hline 2010/Ethiopia ${ }^{2}$ & Cross-sectional & 1,994 women & Being literate and married to an illiterate \\
\hline 2005/Tanzania ${ }^{24}$ & Cross-sectional & 1,444 women & $\begin{array}{l}\text { Difficulty conceiving or woman had borne five or more children; if her husband or partner had other partners or contributes little } \\
\text { to expenses for her and her children, having not more than a primary education. }\end{array}$ \\
\hline 2004/South Africa ${ }^{1}$ & Cross-sectional & 1,395 women & Child sexual assault, forced first intercourse \\
\hline $\begin{array}{l}\text { 2011/Botswana, } \\
\text { Swaziland } 25\end{array}$ & Cross-sectional & 2074 adults & Forced sex victimization, heavy drinking \\
\hline 2011/Nigeria 26 & Cross-sectional & $\begin{array}{l}3000 \text { men and } \\
\text { women }\end{array}$ & Married female respondents were more likely to experience physical violence than single respondents \\
\hline 2013/Ethiopia7 & Cross-sectional & 647 people & Having HIV \\
\hline
\end{tabular}




\begin{tabular}{|c|c|c|c|}
\hline $\begin{array}{l}\text { Year of publication/ } \\
\text { Location }\end{array}$ & Study design & $\begin{array}{l}\text { Study population/ } \\
\text { sample size }\end{array}$ & Predictors/facilitators \\
\hline 2014/Malawi ${ }^{4}$ & Cross-sectional & $\begin{array}{l}466 \text { young } \\
\text { couples }\end{array}$ & Male dominance, education level and unity were protective against physical IPV for both men and women \\
\hline 2015/Ethiopia 27 & $\begin{array}{l}\text { Cross-sectional } \\
\text { using } \\
\text { Demographic } \\
\text { and Health } \\
\text { Surveys of } 2005 \\
\text { and } 2010\end{array}$ & 4338 couples & $\begin{array}{l}\text { Experiencing emotional, beating husband/partner unprovoked, witnessing IPV against mother, husband/partner consumption of } \\
\text { alcohol, and polygynous marriage. Having a husband/partner with secondary education was protective., husband/partner has sex } \\
\text { with non-marital partners, bottom wealth quintile, polygynous marriage, having a son or only daughters versus no children, and } \\
\text { having a husband/partner employed with in-kind versus cash compensation }\end{array}$ \\
\hline 2010/Tanzania 28 & Cross-sectional & 951 men & Men who reported more lifetime sexual partners, experienced physical violence as a child at home, Education \\
\hline 2018/Ghana29 & $\begin{array}{l}\text { Baseline survey } \\
\text { from a cluster } \\
\text { randomized trial }\end{array}$ & $\begin{array}{l}2126 / \text { men } 18 y r s \\
\text { and above }\end{array}$ & Witnessing abuse of mother and neglect, having multiple partners, substance use and gender inequitable attitudes \\
\hline
\end{tabular}

IPV - intimate partner violence 


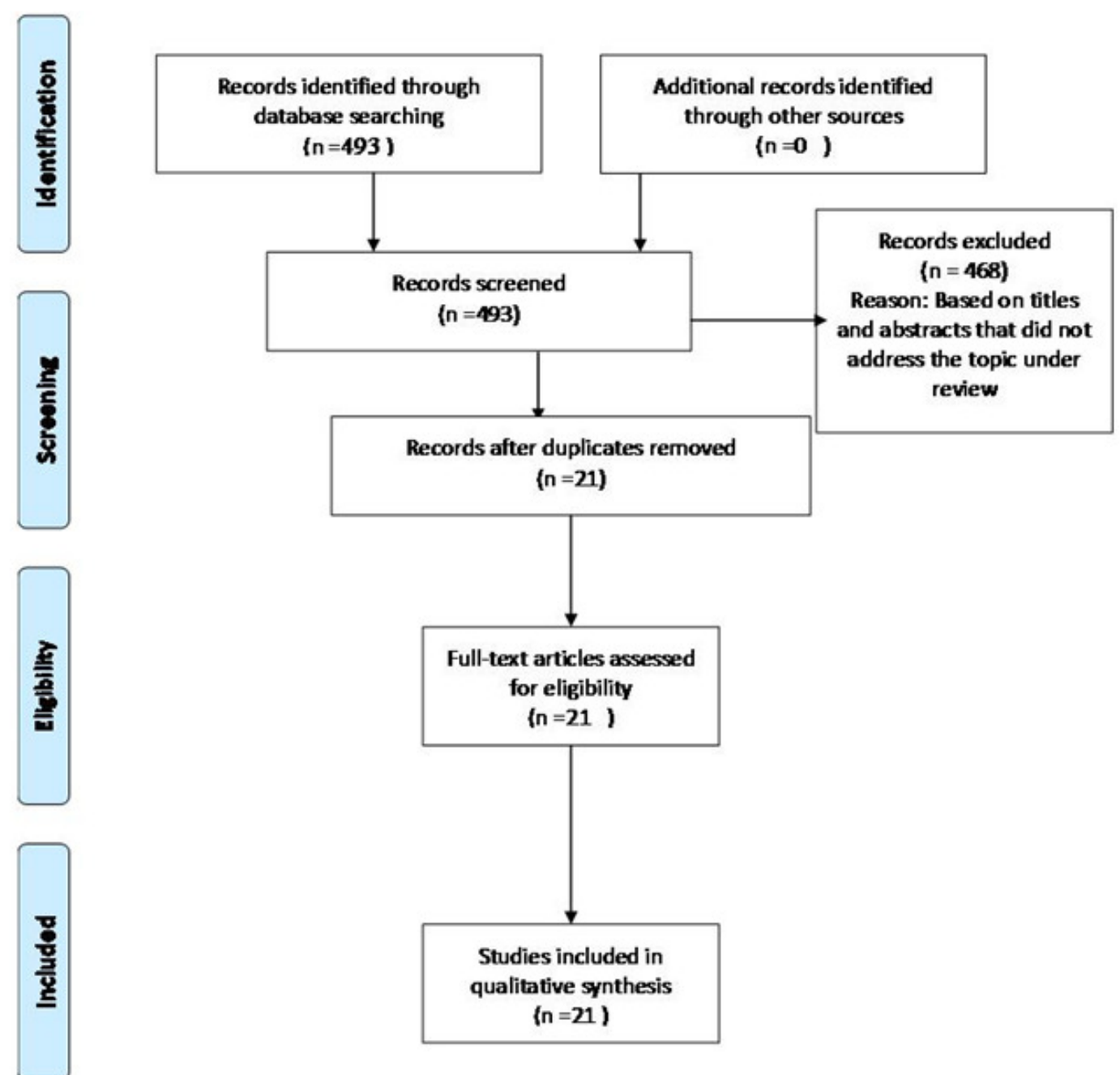

Figure 1. Flow chart of the selection procedure.

\section{STUDY CHARACTERISTICS}

The prevalence of gender-based violence ranges from $11.6 \%$ to $75.6 \%$ (Table 2). Table 3 shows the predictors of genderbased violence. This was categorized into victim factors and perpetrator factors.

\section{VICTIM FACTORS}

Educational status: Six studies documented a significant relationship between the level of education of victims and violence. ${ }^{2-4,9,24,27}$ In all the studies, women with lower levels of education were more likely to experience genderbased violence.

Marital status: Four studies reported a significant association between marital status and gender-based violence. $3,9,12,26$ Women who were married tended to experience gender-based violence than those who were not married.

Occupation (sex work): One study reported engaging in sex work as a predictor. ${ }^{3}$ Women who had engaged in sex work for one to four years were more likely to have experienced gender-based violence.
Previous abuse: Four studies reported a significant relationship between gender-based violence and the experience of abuse in the past.1,11,13,25 Women who had a previous history of abuse were more likely to experience genderbased violence.

Substance abuse by partner: Relationship between substance abuse including alcohol use and gender-based violence was reported in seven studies. ${ }^{3,10,11,13,23,25,27}$ One of these studies reported drug use while the remaining six reported alcohol consumption as predictors. Women whose partners were substance abusers were more likely to experience gender-based violence.

Attitude towards intimate partner violence: One of the studies carried out in Nigeria reported a significant association between intimate partner violence and having an attitude supportive of intimate partner violence (IPV). ${ }^{13}$ Women whose attitudes were supportive of IPV were more likely to experience IPV.

Mental health status: Only one study reported a relationship between mental health status and gender-based violence. This study was carried out in Ghana. ${ }^{11}$ Women who had depression were more likely to encounter genderbased violence. 
Table 2. Studies from sub-Saharan Africa reporting prevalence of gender-based violence (GBV) among women

\begin{tabular}{|c|c|c|c|c|}
\hline Author/year & $\begin{array}{l}\text { Country of } \\
\text { study }\end{array}$ & Study design & $\begin{array}{l}\text { Study population/ } \\
\text { sample size }\end{array}$ & Prevalence of GBV \\
\hline $\begin{array}{l}\text { Alemayehu et } \\
\text { al., } 2015^{3}\end{array}$ & Ethiopia & $\begin{array}{l}\text { Cross- } \\
\text { sectional }\end{array}$ & 250/Women & $75.6 \%$ \\
\hline $\begin{array}{l}\text { Owoaje et al } \\
2012^{13}\end{array}$ & Nigeria & $\begin{array}{l}\text { Cross- } \\
\text { sectional }\end{array}$ & 924/women & $28.2 \%$ \\
\hline $\begin{array}{l}\text { Iliyasu et al., } \\
2011^{12}\end{array}$ & Nigeria & $\begin{array}{l}\text { Cross- } \\
\text { sectional }\end{array}$ & $\begin{array}{l}\text { 300/female university } \\
\text { students }\end{array}$ & $58.8 \%$ \\
\hline $\begin{array}{l}\text { Ogum et al., } \\
2018^{11}\end{array}$ & Ghana & $\begin{array}{l}\text { Cross- } \\
\text { sectional }\end{array}$ & 2000/women & $34 \%$ \\
\hline $\begin{array}{l}\text { Owaka et al } \\
2017^{10}\end{array}$ & Kenya & $\begin{array}{l}\text { Cross- } \\
\text { sectional }\end{array}$ & 238/antenatal women & $66.9 \%$ \\
\hline $\begin{array}{l}\text { Gust et al., } \\
2017^{9}\end{array}$ & Kenya & $\begin{array}{l}\text { Cross- } \\
\text { sectional }\end{array}$ & $\begin{array}{l}8003 \text { (582 girls and } \\
7421 \text { women), }\end{array}$ & $11.6 \%$ (physical violence) \\
\hline $\begin{array}{l}\text { Erickson et al., } \\
2018^{19}\end{array}$ & Uganda & $\begin{array}{l}\text { Cross- } \\
\text { sectional }\end{array}$ & 379 women & $59 \%$ \\
\hline $\begin{array}{l}\text { Rurangirwa et } \\
\text { al., } 2017^{20}\end{array}$ & Rwanda & $\begin{array}{l}\text { Cross- } \\
\text { sectional }\end{array}$ & 921 women & $\begin{array}{l}\text { Physical, sexual, psychological } \\
\text { violence and controlling } \\
\text { behaviour during pregnancy were } \\
10.2 \%, 9.7 \%, 17.0 \% \text {, } \\
20.0 \% \text { respectively }\end{array}$ \\
\hline $\begin{array}{l}\text { Decker et al., } \\
2016^{21}\end{array}$ & South Africa & $\begin{array}{l}\text { Cross- } \\
\text { sectional }\end{array}$ & 1817 FSW & $60 \%$ \\
\hline $\begin{array}{l}\text { Abebe et al } \\
2016^{22}\end{array}$ & Ethiopia & $\begin{array}{l}\text { Cross- } \\
\text { sectional }\end{array}$ & $\begin{array}{l}\text { married pregnant } \\
\text { women/2021 }\end{array}$ & $44.5 \%$ \\
\hline $\begin{array}{l}\text { McCloskey et al } \\
2005^{24}\end{array}$ & Tanzania & $\begin{array}{l}\text { Cross- } \\
\text { sectional }\end{array}$ & 1,444 women & $21 \%$ \\
\hline & & & & $\begin{array}{l}\text { Physical/sexual partner violence } \\
(55.5 \%) \text {, adult sexual }\end{array}$ \\
\hline $\begin{array}{l}\text { Dunkle et al., } \\
2004^{1}\end{array}$ & South Africa & $\begin{array}{l}\text { Cross- } \\
\text { sectional }\end{array}$ & 1,395 women & $\begin{array}{l}\text { assault by non-partners }(7.9 \%) \text {, child } \\
\text { sexual assault } \\
(8.0 \%) \text {, and forced first intercourse } \\
(7.3 \%)\end{array}$ \\
\hline $\begin{array}{l}\text { Tsai et al., } \\
2011^{25}\end{array}$ & $\begin{array}{l}\text { Botswana and } \\
\text { Swaziland }\end{array}$ & $\begin{array}{l}\text { Cross- } \\
\text { sectional }\end{array}$ & 2074 adults & $\begin{array}{l}10.3 \% \text { in Botswana and } 11.4 \% \text { in } \\
\text { Swaziland }\end{array}$ \\
\hline
\end{tabular}

GBV - gender-based violence, FSW - female sex worker

Age: The age of respondents was documented by two studies as a predictor of gender-based violence. ${ }^{10,20}$ Younger women were more likely to face gender-based violence when compared to their older counterparts.

Socio-economic status: Two studies reported a significant association between socioeconomic status and genderbased violence. ${ }^{20,27}$ Women in families with low socioeconomic status were more likely to be abused.

Residence: Association was found between the place of residence and gender-based violence in two studies. ${ }^{12,20}$ One of the studies reported that women living in urban areas were more likely to experience gender-based violence ${ }^{20}$ while the second study reported campus residence as a predictor. $^{12}$

Sexual history and relationship dynamics: Five studies documented a significant relationship between sexual history and gender-based violence. ${ }^{11,21,23,24,27}$ Women whose spouses had multiple sexual partners were more likely to be abused. One study reported that male dominance was a predictor of gender-based violence. ${ }^{4}$

Social support (having ever lived with a partner's family): Two studies reported a significant relationship be- tween social support and gender-based violence. ${ }^{20,22} \mathrm{Hav}$ ing lived with a partner's parents was shown to be less likely associated with GBV.

Parity and family size: Two studies reported that parity and family size were significantly associated with GBV. ${ }^{24,27}$ Women who did not have children or who had difficulty in bearing children, women who had only a son or only a daughter and women who had more than five children were more likely to experience GBV.

Dowry/cultural factor: Women who had their dowry paid were less likely to experience GBV. This was reported by only one study. ${ }^{22}$

Having experienced abuse of mother: Two studies reported that women who experienced abuse of mother in the past, were more likely to be abused. ${ }^{11,27}$

\section{PERPETRATOR FACTORS}

Two studies were carried out among men alone and predictors reported in these studies include sexual history, previous experience of abuse, educational status, substance use, gender-biased attitude, and having experienced abuse of mother. ${ }^{28,29}$ Men who had multiple sexual partners, who 
Table 3. Predictors of gender based violence

\begin{tabular}{|c|c|c|}
\hline Predictor type & Predictors & Countries \\
\hline \multicolumn{3}{|l|}{ Victim factors: } \\
\hline & Educational status $2-4,9,24,27$ & Ethiopia, Kenya, Malawi \\
\hline & Marital status $3,9,12,26$ & Ethiopia, Nigeria, Kenya \\
\hline & Occupation: sex work ${ }^{3}$ & Ethiopia \\
\hline & Previous abuse victim 1,11,13,25 & $\begin{array}{l}\text { Nigeria, Ghana, South Africa, Botswana } \\
\& \text { Swaziland }\end{array}$ \\
\hline & Substance abuse by Partner3,10,11,13,23,25,27 & $\begin{array}{l}\text { Nigeria, Ghana, Kenya, South Africa, } \\
\text { Botswana \& Swaziland, Ethiopia }\end{array}$ \\
\hline & Attitude towards IPV13 & Nigeria \\
\hline & Mental health status ${ }^{11}$ & Ghana \\
\hline & Age $^{10,20}$ & Kenya, Rwanda \\
\hline & Socioeconomic status 20,27 & Ethiopia, Rwanda \\
\hline & Residence ${ }^{12,20}$ & Nigeria, Rwanda \\
\hline & $\begin{array}{l}\text { Sexual history and Relationship dynamics: control by male } \\
\text { partner, Multiple Sexual Partners } 4,11,21,23,24,27\end{array}$ & $\begin{array}{l}\text { Ghana, South Africa, Ethiopia, Tanzania, } \\
\text { Malawi }\end{array}$ \\
\hline & Social support: Having ever lived with partner's family 20,22 & Ethiopia, Rwanda \\
\hline & Parity and family size 24,27 & Tanzania, Ethiopia \\
\hline & Dowry/cultural 22 & Ethiopia \\
\hline & Having experienced abuse of mother ${ }^{11,27}$ & Ghana, Ethiopia \\
\hline \multicolumn{3}{|c|}{ Perpetrator factors: } \\
\hline & Sexual History 28,29 & Tanzania, Ghana \\
\hline & Previous abuse victim 28,29 & Tanzania, Ghana \\
\hline & Educational status 28,29 & Tanzania, Kenya \\
\hline & Substance use $\mathrm{e}^{29}$ & Ghana \\
\hline & Gender-biased attitude 29 & Ghana \\
\hline & Having experienced abuse of mother 29 & Ghana \\
\hline
\end{tabular}

IPV - intimate partner violence

were abuse victims, who had low educational status, who were substance abusers, who had gender inequitable attitudes and who experienced abuse of mothers in the past were more likely to be perpetrators of gender-based violence.

\section{DISCUSSION}

The findings of this review indicate the persistence of gender-based violence in our society and also reveals its associated factors. The prevalence of gender-based violence is still high in sub-Saharan Africa. Studies that reported a prevalence of greater than $50 \%$ in this review include Ethiopia, Nigeria, Kenya, Uganda, and South Africa. Despite interventions geared towards reducing the rate of genderbased violence, its prevalence continues to be high. This finding may be explained by the fact that in the African culture, women are expected to be submissive to their male partners and any attempt to resist is taken to be unacceptable. As a result of this, women do not readily report cases of violence but seek other measures to settle the problem and in so doing, the perpetrators are not cautioned and do not receive adequate punishment. A study that compared rates of formal and informal reporting of gender-based violence showed a low rate of formal reporting. ${ }^{8}$ Further- more, cultural traditions exist that reinforce seeing women as possessions and properties of men. This may have contributed to the high prevalence.

Both victim and perpetrator factors associated with gender-based violence were identified in this review. The victim factors include: Educational status, marital status, occupation, previous abuse victim, previous abuse perpetrator, substance abuse, attitude towards IPV, mental health status, age, socioeconomic status, residence, sexual history and relationship, dynamics: control by male partner, multiple sex partners, social support: having ever lived with partner's family, parity and family size. Perpetrator factors include sexual history, previous experience of abuse, educational status, substance use, gender-biased attitude, and having experienced abuse of the mother. The majority of the studies focused on the victims and these were mostly women. This points out the need for further research to be carried out on the role of perpetrators. This will help identify ways of curbing gender-based violence. Also, it may be necessary to carry out further studies among men to uncover the rate of gender-based violence against men. Factors reported by the majority of countries are factors peculiar to the spouse/partner such as substance abuse, male dominance and having multiple sexual partners. Socio-demographic factors were also reported in up to five countries. 
This shows the similarity in these countries and further buttresses the effect of the African culture on gender-based violence.

Several factors such as socio-demographic factors, factors peculiar to the individual, family factors, spouse's/partner's habit, and experience in the past have been implicated in the perpetuation of gender-based violence. Socio-demographic factors reported in the reviewed studies include being married, lower level of education, religious affiliation, ethnicity, age, low socioeconomic status, living in urban areas and poor social support. Lack of formal education means low female literacy and lack of empowerment which has a direct effect on the risk of intimate partner violence and well-being in general. ${ }^{10,11}$ Formal education leads to an improvement in knowledge and increases access to information necessary in making demands for social change. ${ }^{11}$ Women who are more educated are more likely to have better information for the management of interpersonal relationships. Additionally, women who have higher education are more likely to have paid jobs, and a better balance of power in marriage. ${ }^{11}$ IPV risk is known to be higher in households that are economically disadvantaged or under economic stress. ${ }^{11}$

Factors peculiar to individual include engaging in sex work, drug use, depression, disability, having had multiple sexual partners in past year, having history of forced sex in the previous 12 months, risky sexual behaviours, forced first intercourse, being HIV positive, having a husband/partner employed with in-kind versus cash compensation. Individual peculiarities have a role to play in gender-based violence. The problem of gender-based violence can be addressed at the individual level. The root causes of violence are associated with attitudes and beliefs that promote and/ or condone violence against women and girls. Women need to be educated on the need to abstain from these risky behaviours and attitudes that can lead to the perpetuation of violence. Enlightenment programs aimed at equipping women and girls with the necessary information are essential.

Factors due to spouse's/partner's habits include alcohol consumption by a partner, male partner dominance, male partner infidelity, illiterate spouse, contributing little to expenses for the partner and her children, having more lifetime sexual partners. Alcohol consumption is a major habit of partners that encourages the perpetration of GBV. Five of the reviewed studies reported alcohol intake by a partner as a predictor of gender-based violence. ${ }^{10,11,13,25,27}$ Male dominance was also reported as a predictor of gender-based violence. Men are seen as dominant and the head of household and women are largely expected to be submissive and serve her primary role as mother and caretaker.

Factors due to previous experience include previous experience of psychological abuse and sexual abuse, previous engagement in a physical fight, witnessing the abuse of mother, the experience of childhood sexual abuse. Experiencing a particular lifestyle over time can lead to the acceptability of such lifestyle especially as it concerns children. This is in accordance with psychosocial concepts from the Social Learning Theory that have shown that individuals learn how to behave through observing and imitating important individuals in their social environment. ${ }^{29}$ Family factors including having no children/having problems conceiving or having borne five or more children were also identified in this review. Women are considered responsible for growing the family size particularly in the African culture and failure to do so attracts negative judgment from society. It is therefore important to engage and enlighten community leaders and stakeholders on the need to amend certain cultural beliefs that encourage gender-based violence.

This review further revealed that having a husband/partner with secondary education was protective. The need for formal education for both men and women cannot be overemphasized. Pregnant women who had ever lived with their partner's family were less likely to experience recent intimate partner violence. This shows the essence of the extended family system which is mostly practiced in Africa. The extended family system should be encouraged and not be put aside completely as it can contribute to reducing the rate of violence against women. Dowry payment was also reported to decrease intimate partner violence during a recent pregnancy. Dowry payment is a part of African culture that is still being practiced. This shows that certain cultural factors are of enormous benefit in improving the well-being of women and girls.

\section{STUDY LIMITATIONS}

The review only focused on quantitative studies. However, the topic may be better understood qualitatively. The review also excluded French literature.

\section{CONCLUSION}

An inter-sectoral approach is needed to address the issue of gender-based violence. This will include involving the ministry of education, ministry of health, social welfare, women affairs, judiciary, security agencies among others. Community-based prevention programmes targeted at transforming certain cultural beliefs also need to be developed.

\section{ACKNOWLEDGEMENTS}

The review was supported by the African Institute for Health Policy and Health Systems, Ebonyi State University, Nigeria.

\section{FUNDING}

This review was not funded by any funding agency.

\section{CONFLICT OF INTEREST}

The authors completed the Unified Competing Interest form at http://www.icmje.org/coi_disclosure.pdf (available upon request from the corresponding author), and declare no conflicts of interest. 


\section{CORRESPONDENCE TO:}

Dr. Ifeyinwa Chizoba Akamike

African Institute for Health Policy and Health Systems Ebonyi State University
P.M.B. 053

Abakaliki, Nigeria

ifeyakamike@gmail.com

ifeychima@yahoo.com 


\section{REFERENCES}

1. Dunkle KL, Jewkes RK, Brown HC, Yoshihama M, Gray GE, McIntyre JA. Prevalence and Patterns of Gender-based Violence and Revictimization among Women Attending Antenatal Clinics in Soweto, South Africa. Am J Epidemiol. 2004;160(3):230-239. doi:10.1 093/aje/kwh194

2. Deyessa N, Berhane Y, Ellsberg M, Emmelin M, Kullgren G, Högberg U. Violence against women in relation to literacy and area of residence in Ethiopia. Glob Health Action. 2010;3(1):2070. doi:10.3402/gha.v 3i0.2070

3. Alemayehu M, Yohannes G, Damte A, et al. Prevalence and predictors of sexual violence among commercial sex workers in Northern Ethiopia. Reprod Health. 2015;12(1). doi:10.1186/s12978-015-0036-5

4. Conroy AA. Gender, power, and intimate partner violence: a study on couples from rural Malawi. $J$ Interpers Violence. 2013;29(5):866-888. doi:10.1177/0 $\underline{886260513505907}$

5. Women for Women International. Series: What Does That Mean? Gender based Violence. Published 2017. Accessed January 16, 2019. https://www.women forwomen.org

6. Heise L, Ellsberg M, Gottmoeller M. A global overview of gender-based violence. Int J Gynecol Obstet. 2002;78:S5-S14. doi:10.1016/s0020-7292(02)0 $\underline{0038-3}$

7. Hassen F, Deyassa N. The relationship between sexual violence and human immunodeficiency virus (HIV) infection among women using voluntary counseling and testing services in South Wollo Zone, Ethiopia. BMC Res Notes. 2013;6:271. doi:10.1186/175 6-0500-6-271

8. Palermo T, Bleck J, Peterman A. Tip of the iceberg: reporting and gender-based violence in developing countries. Am J Epidemiol. 2014;179(5):602-612. doi:1 $\underline{0.1093 / \mathrm{aje} / \mathrm{kwt} 295}$

9. Gust DA, Pan Y, Otieno F, Hayes T, Omoro T, Phillips-Howard PA. Factors associated with physical violence by a sexual partner among girls and women in rural Kenya. J Glob Health. 2017;7:020406.

10. Owaka IO, Nyanchoka MK, Atieli HE. Intimate partner violence in pregnancy among antenatal attendees at health facilities in West Pokot county, Kenya. Pan Afr Med J. 2017;28:229. doi:10.11604/pam j.2017.28.229.8840
11. Ogum Alangea D, Addo-Lartey AA, Sikweyiya Y, et al. Prevalence and risk factors of intimate partner violence among women in four districts of the central region of Ghana: baseline findings from a cluster randomised controlled trial. PLOS ONE. 2018;13(7):e0200874. doi:10.1371/journal.pone.0200 $\underline{874}$

12. Iliyasu Z, Abubakar IS, Aliyu MH, Galadanci HS, Salihu HM. Prevalence and correlates of gender-based violence among female university students in Northern Nigeria. Afr J Reprod Health. 2011;15:111-119.

13. Owoaje ET, OlaOlorun FM. Women at risk of physical intimate partner violence: a cross-sectional analysis of a low-income community in southwest Nigeria. Afr J Reprod Health. 2012;16(1):43-53.

14. World Health Organisation. Multi-country study on women's health and gender based violence. Published 2005. Accessed January 15, 2019. https://w ww.who.int

15. Ribeiro MRC, da Silva AAM, Alves MTSS de B e, et al. Effects of Socioeconomic Status and Social Support on Violence against Pregnant Women: A Structural Equation Modeling Analysis. PLOS ONE. 2017;12(1):e0170469. doi:10.1371/journal.pone.0170 $\underline{469}$

16. Shamseer L, Moher D, Clarke M, et al. Preferred reporting items for systematic review and metaanalysis protocols (PRISMA-P) 2015: elaboration and explanation. BMJ. 2015;349(jan02 1):g7647. doi:10.11 36/bmi.g7647

17. Wardle J, Steel A. Systematic reviews in integrative medicine: a clinician's guide to publication. Adv Integr Med. 2015;2(2):103-109. doi:1 0.1016/j.aimed.2015.09.001

18. Njagi P, Arsenijevic J, Groot W. Understanding variations in catastrophic health expenditure, its underlying determinants and impoverishment in SubSaharan African countries: a scoping review. Syst Rev. 2018;7:136. doi:10.1186/s13643-018-0799-1

19. Erickson M, Goldenberg SM, Master A, et al. Interpersonal and structural contexts of intimate partner violence among female sex workers in conflict-affected northern Uganda. Women Health. 2017;58(7):759-773. doi:10.1080/03630242.2017.1342 742 
20. Rurangirwa AA, Mogren I, Ntaganira J, Krantz G. Intimate partner violence among pregnant women in Rwanda, its associated risk factors and relationship to ANC services attendance: a population-based study. BMJ Open. 2017;7(2):e013155. doi:10.1136/bmjope $\underline{\mathrm{n}-2016-013155}$

21. Decker MR, Lyons C, Billong SC, et al. Genderbased violence against female sex workers in Cameroon: prevalence and associations with sexual HIV risk and access to health services and justice. Sex Transm Infect. 2016;92(8):599-604. doi:10.1136/sextra ns-2015-052463

22. Abebe Abate B, Admassu Wossen B, Tilahun Degfie T. Determinants of intimate partner violence during pregnancy among married women in Abay Chomen district, Western Ethiopia: a community based cross sectional study. BMC Women's Health. 2016;16:16. doi:10.1186/s12905-016-0294-6

23. Pitpitan EV, Kalichman SC, Eaton LA, et al. Gender-based violence, alcohol use, and sexual risk among female patrons of drinking venues in Cape Town, South Africa. J Behav Med. 2013;36(3):295-304. doi:10.1007/s10865-012-9423-3

24. McCloskey LA, Williams C, Larsen U. Gender inequality and intimate partner violence among women in Moshi, Tanzania. Int Fam Plan Perspect. 2005;31(03):124-130. doi:10.1363/3112405
25. Tsai AC, Leiter K, Heisler M, et al. Prevalence and correlates of forced sex perpetration and victimization in Botswana and Swaziland. Am J Public Health. 2011;101(6):1068-1074. doi:10.2105/ajph.201 $\underline{0.300060}$

26. Oladepo O, Yusuf OB, Arulogun OS. Factors influencing gender based violence among men and women in selected states in Nigeria. Afr J Reprod Health. 2011;15:78-86.

27. Thomson DR, Bah AB, Rubanzana WG, Mutesa L. Correlates of intimate partner violence against women during a time of rapid social transition in Rwanda: analysis of the 2005 and 2010 demographic and health surveys. BMC Women's Health. 2015;15:96. doi:10.1186/s12905-015-0257-3

28. Maman S, Yamanis T, Kouyoumdjian F, Watt M, Mbwambo J. Intimate Partner Violence and the Association With HIV Risk Behaviors Among Young Men in Dar es Salaam, Tanzania. J Interpers Violence. 2009;25(10):1855-1872. doi:10.1177/08862605093544 $\underline{98}$

29. Chirwa ED, Sikweyiya Y, Addo-Lartey AA, et al. Prevalence and risk factors of physical or sexual intimate violence perpetration amongst men in four districts in the central region of Ghana: Baseline findings from a cluster randomised controlled trial. PLoS ONE. 2018;13(3):e0191663. doi:10.1371/journa l.pone. 0191663 